\title{
EDITORIAL
}

\section{FUNDAMENTOS TEÓRICOS DE ENFERMERÍA, UNA CARTA DE NAVEGACIÓN PARA LA PRÁCTICA}

$\mathrm{E}^{1}$ núcleo disciplinar de enfermería es el cuidado de las personas, familia y comunidad, miradas desde un punto de vista contextual, por lo tanto, el cuerpo de conocimientos se relaciona con éste.

Las teorías y modelos son consideradas como una "carta de navegación" para la práctica. Refuerzan la identidad de los profesionales de enfermería al crear un pensamiento y un lenguaje compartido entre quienes las aplican; favorecen la gestión del cuidado de forma sustentada y efectiva; fortalecen la importancia del ser humano como centro de atención para el cuidado y, de esta manera, permiten identificar con mayor claridad cuál es la contribución profesional que realizamos a los servicios de salud. Por lo tanto, los fundamentos teóricos son herramientas ineludibles para el razonamiento, el pensamiento crítico y generación de innovaciones en el cuidado. Apoyan a que los profesionales de enfermería puedan emplear y manejar toda la información acerca del paciente, pues facilitan la valoración, planificación y evaluación de los resultados de lo que hacemos.

La construcción, aplicación y renovación de estas bases teóricas de enfermería generan el avance de nuestra disciplina. 